Country-level entrepreneurial attitudes and activity through the years: A panel data analysis using fsQCA

Malcolm J. Beynon a, Paul Jones b, David Pickernell c

a Cardiff Business School, Cardiff University, Cardiff, CF10 3EU, UK. E:mail:

beynonmj@cardiff.ac.uk

b School of Management, Swansea University, Swansea, SA1 8EN, UK E mail:

w.p.jones@ @wansea.ac.uk

c School of Business, University of Portsmouth, Portsmouth, UK. E mail:

david.pickernell@port.ac.uk 


\title{
Country-level entrepreneurial attitudes and activity through the years: A panel data analysis using fsQCA
}

\begin{abstract}
This paper presents a novel longitudinal study of entrepreneurial attitudes and activity. The study uses fuzzy-set qualitative comparative analysis (fsQCA) and builds on a previous crosssectional cross-country investigation. Data for 2007-2017 from the Global Entrepreneurship Monitor (GEM) project are used to compare 108 countries in terms of entrepreneurial attitudes and activity. Considering each country-year GEM observation as a case (in fsQCA terms), causal recipes are found and then interpreted. Elucidation of the nature of the considered panel data set is given by i) analyzing the causal recipes' consistency across different years and ii) investigating individual countries and their consistency across recipes and years. The study has policy management and future research implications based on the heterogeneous year-on-year relationships identified between entrepreneurial attitudes and activity across different countries. Panel fsQCA and year-specific cross-sectional fsQCA are also compared.
\end{abstract}

Keywords: fsQCA, Entrepreneurial attitudes, longitudinal, GEM, Entrepreneurial activity 


\section{Introduction}

Entrepreneurial activity is often regarded as crucial for nations' economic development (Van Stel, Carree, \& Thurik, 2005), leading policymakers to focus on areas that promote such activity (Ács \& Szerb, 2007). As studies intimate, however, entrepreneurship typically has a "U-shaped" relationship with levels of economic development (Ács, Desai, \& Hessels, 2008). More broadly, the entrepreneurial attitudes that drive entrepreneurial activity, as well as entrepreneurship itself and its subsequent effects, are unevenly geographically dispersed (Beynon, Jones, \& Pickernell, 2016, 2018). Taken together, this situation makes entrepreneurial activity and its drivers an area of continuing research interest and one in crucial need of considering national-level characteristics.

Marcotte (2013) noted that measurement of entrepreneurial activity across national contexts is a relatively recent and underrepresented area of investigation. The analysis of entrepreneurial attitudes and activity across countries performed in Beynon et al. (2016), focused on only a single year of data. However, the differential longitudinal impact of economic shocks on nations' entrepreneurial activity and the drivers of this activity is also of fundamental importance in this debate. For example, Congregado, Golpe, and Parker (2012) found that long-run rates of entrepreneurship in Spain and the USA are affected differently by the economic shocks and policies that are inherent in the business cycle. An example of one such shock is the 2008 global financial crisis (IMF, 2009), which offers an opportunity to compare the experiences of different countries in the years following this shock.

The Global Entrepreneurship Monitor (GEM) project from which Beynon et al.'s (2016) study took its data has collected data on entrepreneurial behavior and attitudes for over 18 years from over 100 participating countries (GEM, 2019). Although Marcotte (2013) has noted that shortcomings in GEM surveys have been criticized (e.g., Baumol et al., 2007; Hindle, 2006), GEM has contributed to the development of research comparing 
entrepreneurship in different contexts. The internationally recognized annual GEM survey employed in Beynon et al.'s (2016) study is regularly used to research entrepreneurial attitudes and the activity that drives these attitudes in multiple country settings (Beynon et al., 2016; Bosma \& Schutjens, 2011). GEM data sets are also widely used to evaluate and contrast entrepreneurial attitudes and activity, and GEM-based studies are published in leading entrepreneurship and economics journals (e.g., Beynon et al., 2018; Roper \& Scott, 2009; Wong, Ho, \& Autio, 2005).

This study illustrates the benefits of longitudinal research in this area, not only in the evaluation of the stability of causal recipes for an outcome but also the degree of fluctuations in the recipes associated with different countries over time and the conditions that make up these recipes. To illustrate these benefits and enable comparison with Beynon et al.'s (2016) study, fuzzy-set qualitative comparative analysis (fsQCA) is used as the primary method (Ragin, 2008) to analyze the relationship between entrepreneurial attitudes and activity.

This study therefore uses the same model as in Beynon et al.'s (2016) single-year study but considers evidence for the years 2007 to 2017 . Results in this study are directly comparable to those reported by Beynon et al. (2016), specifically the causal recipes found using fsQCA. Users of fsQCA will also be interested to observe how stable a single-year analysis is compared to analysis using data from multiple years. With an emphasis on the comparable graphical presentation of results, an opportunity for building a clear comparative understanding is also provided. Overall, this approach offers reliable, robust longitudinal results, making it possible to evaluate and contrast the stability of entrepreneurial attitudes and activity and the causal recipes generated within and between countries over a substantial period.

The next section of the manuscript discusses the measures of entrepreneurial activity and attitudes used in the study, including an appreciation of the related year-on-year interest 
across countries. Next, a description of the method, data, and initial calibration required for fsQCA is given. An initial fsQCA analysis is then undertaken using the country-level panel data set, including necessity analysis, truth table elucidation, and sufficiency analysis. A subsequent fsQCA-related discussion of the panel data feature of the data set is undertaken, including the between-year and within-country consistency for the established causal recipes. The final section offers conclusions and directions for future research.

\section{Measures of entrepreneurial attitudes and activity}

Previous studies have identified total early-stage entrepreneurial activity (TEA) as an important, well-used measure of the development of the enterprise culture and small businesses that are necessary for business growth across nations (Uhlaner \& Thurik, 2007). Identification of the relevant variables in driving TEA is first derived using the pre-existing GEM conceptual framework (see Kelley, Singer, \& Herrington, 2015, p.12). The basic version is shown in Figure 1.

\section{Insert Figure 1 here.}

A range of factors, shown in Figure 1, drive TEA across economies. Beynon et al. (2018) have previously analyzed how self-perceptions about entrepreneurship (SPaE) are driven by economic state of development, entrepreneurial framework conditions, and entrepreneurial status. However, the roles of these SPaE have been found to be of specific relevance (directly and indirectly) to entrepreneurial activities in the form of TEA (see Beynon et al., 2016; Bosma and Schutjens, 2011). The rest of this section describes the TEA outcome and four SPaE-related conditions also considered in Beynon et al. (2016). These conditions collectively measure what are described in this study as entrepreneurial attitudes and activities, namely perceived opportunities (Prcvd_Opps), perceived capabilities (Prcvd_Caps), fear of failure (Fr_of_Flr), and entrepreneurial intention (Entrp_Intnt). 


\subsection{Total early-stage entrepreneurial activity (TEA)}

The specific TEA measure used in this study is defined as nascent entrepreneurship (people actively involved in business startup) plus the stage directly after startup (ownermanagers of businesses between 3-42 months old; Bosma, Wennekers, \& Amorós, 2012) as a percentage of the adult (18-64) population (Wennekers, van Stel, Thurik, \& Reynolds, 2005). As identified in Marcotte (2013), this is a specific measure of entrepreneurial activity focused on the emergence of new activity in small business establishments. Thus, it does not consider existing small and medium-sized enterprises' (SMEs') activities or indeed entrepreneurial activities within larger organizations. It is also affected by the level of economic development of a given economy (Beynon et al., 2016; Van Stel et al., 2005), giving country-level analysis an added degree of importance.

\subsection{Perceived opportunities (Prcvd_Opps)}

The issue of entrepreneurial opportunities is a current, topical issue in entrepreneurship research (Braver \& Danneels, 2018; Davidsson, 2015). Perceived opportunities are a fundamental component of entrepreneurial behavior that contributes to both business startup and growth (Gundry \& Welsch, 2001). This study uses Bosma et al.'s (2012) definition of perception of entrepreneurial opportunities, namely the percentage of individuals who believe that opportunities to start a business in the area where they reside exist. Perceived opportunity can influence opportunity entrepreneurship, generating greater business and economic growth than necessity-based entrepreneurial behavior (Ács, 2006). 


\subsection{Perceived capabilities (Prcvd_Caps)}

A well-established body of academic literature identifies the range of business capabilities that effective entrepreneurs require (Cui, Sun, Xiao, \& Zhao, 2016; Karra, Phillips, \& Tracey, 2008; McGee, Peterson, Mueller, \& Sequeira, 2009). The perceptions people have of both the environment (opportunity) and their capabilities given those opportunities can then drive them toward, or away from, entrepreneurship (Ács et al., 2008), which also differentiates independent entrepreneurs and entrepreneurial employees (Nyström, 2012). In this study, perceived capabilities are measured as the percentage of entrepreneurial individuals in each country who believe they have the required competencies (skills, knowledge, and experience) for business startup (Bosma et al., 2012). Such self-perceptions differ across countries. In India, for example, Gupta, Guo, Canever, Yim, Sraw, \& Liu, (2014) have reported high levels of individuals' self-perceived ability to start or operate a business, partly reflecting national human capital development through specific entrepreneurship education programs. In contrast, in post-socialist emerging economies, perceived entrepreneurial knowledge and skills are often lower (Manolova, Eunni, \& Gyoshev, 2008). However, perceived lack of entrepreneurial knowledge and skills might also still push individuals into entrepreneurship (by necessity), meaning that entrepreneurial activity may be driven by both ends of the perceived ability spectrum (Burton, Sørensen, \& Dobrev, 2016) and may be linked to the presence, absence, and nature of perceived opportunities.

\subsection{Fear of failure (Fr_of_Flr)}

Entrepreneurs often experience a fear of failure in relation to the startup and development process (Urbano, Aparicio, \& Audretsch, 2018), which is unsurprising given that many individuals are risk averse (Arenius \& Minniti, 2005). The level of this fear of 
failure, however, differs considerably between countries (Anwar ul Haq, Usman, Hussain, and Anjum, 2014). A high number of individuals expressing fear of failure results in a low national rate of entrepreneurial entry (Vaillant \& Lafuente, 2007). Using data from the GEM project, Wyrwich, Stuetzer, and Sternberg (2016) found that environmental context (related to opportunity and capability) is also important in determining how fear of failure and observed entrepreneurial opportunity affect one another. This study uses the GEM definition of fear of failure, which is measured as an entrepreneur's fear of business failure during startup (Bosma et al., 2012).

\subsection{Entrepreneurial intention (Entrp_Intnt)}

Souitaris, Zerbinati, and Al-Laham (2007) suggest that intention is often the most effective predictor of behavior, particularly when such behavior is rare, is difficult to observe, or has unpredictable time lags, all of which apply to entrepreneurial activity. Entrepreneurial intention is defined here as the expectation of individuals to start a business (Bosma et al., 2012). This definition corresponds to the GEM definition specifically relating to individuals, excluding those already involved in entrepreneurial activity, who intend to start a business within the next three years. Such entrepreneurial intent can be regarded as personally and socially, including culturally, driven (Autio, Keeley, Klofsten, Parker, \& Hay, 2001). However, it is also affected by local economic conditions (Kibler, Kautonen, \& Fink, 2014), so it is thereby also affected by perceived opportunities, capabilities, and risks of failure.

\subsection{Configurational conceptualization and longitudinal approach}

The discussion in the previous sections highlights the potential interaction effects between the different entrepreneurial attitudes themselves, as well as their potential effects on entrepreneurial activity (TEA). Figure 2 shows a conceptual framework for the ways in which 
entrepreneurial attitudes and activities may drive TEA, where TEA results from the complex interactions between these attitudes and activities.

\section{Insert Figure 2 here.}

In the conceptual framework in Figure 2, P1 to P6 show (for the purposes of simplification) the six pairs of conditions that have the potential to drive the presence or absence of TEA either by themselves or in combination with other pairs. These pairs also suggest that there is likely to be more than one causal combination explaining the presence and absence of TEA.

As in Beynon et al.'s (2016) study, this discussion identifies four interrelated entrepreneurial attitudes and activity conditions that potentially affect TEA. Beynon et al. (2016), however, were unable to evaluate potential year-on-year changes in the conditions and their effects on TEA across countries. These changes and effects are also potentially important because, as Beynon et al. (2018) remarked, these entrepreneurial attitudes and activity conditions are themselves affected not only by the state of development of the economy but also by the entrepreneurial framework conditions (such as government regulations, research and development activity, and entrepreneurship education) and the status of entrepreneurship itself. All of these factors are subject to policy interventions and thus may vary over time, potentially causing one or more of the entrepreneurial attitudes and activity conditions to change, with possible knock-on effects on TEA. Indeed, such policy interventions are often designed for this reason. Hence, there is a need to use a method that is able to examine potential impacts of combinations of these factors on entrepreneurial activity in different types of national economies over time. 


\section{Method, data, and initial calibration}

This section presents basic information on the method employed in this study, the data considered, and the preliminary calibration of conditions and the outcome (required for use with fsQCA).

\subsection{Method}

In Ragin's (2008) book Redesigning Social Inquiry: Fuzzy Sets and Beyond, the author gives a full description of fuzzy-set qualitative comparative analysis (fsQCA), including the surrounding issues of such a set-theoretic approach. As a technique, it is enjoying increasing popularity in business and the social sciences (Roig-Tierno, Huarng, \& Ribeiro-Soriano, 2016; Schneider \& Wagemann, 2012), particularly entrepreneurship and innovation research (Kraus, Ribeiro-Soriano, \& Schüssler, 2018). The underpinnings of the analysis, which is set theoretical in nature, include the use of combinatorial logic, fuzzy-set theory, and Boolean minimization to detect the combinations of case conditions that may be necessary or sufficient to produce an outcome (Kent \& Olsen, 2008). Thus, fsQCA follows an inductive approach (Schneider \& Wagemann, 2010), in this case identifying configurational relationships between the conditions (entrepreneurial attitudes) and outcome (entrepreneurial activity).

As a technique, fsQCA has also been the subject of development, notably in terms of its appropriate employment with panel data (Garcia-Castro \& Ariño, 2016). This development specifically acknowledges the inherent panel data structure and proposes a new suite of general descriptive measures for evaluating set-theoretic relationships for such panel data. Here, the focus is on consistency-oriented developments (see Appendix B), namely pooled consistency (POCONS), between consistency (BECONS), and within consistency (WICONS; see also Guedes, da Conceição Gonçalves, Soares, \& Valente, 2016). Misangyi et 
al. (2017, p. 274) noted that these measures offer a promising approach to incorporating time into fsQCA to enable "longitudinal set-theoretic research." This study is believed to be the first attempt to employ these measures with a large entrepreneurship data set.

\subsection{Data}

The data considered here were taken from the GEM (2007-2017) surveys (panel data set available at https://www.gemconsortium.org/data). Descriptions of the considered conditions (entrepreneurial attitudes) and outcome (entrepreneurial activity) were discussed in the previous section (see also Beynon et al., 2016, for a full description). For the years 2007 to 2017, 638 country-year observations were considered. Not all countries were included in every considered year because of the churn of participants at each instance of the GEM survey for a variety of reasons, including financial and political. In total, 108 countries were covered throughout the considered years. The frequency of their presence in the data set ranges from 1 to 11 occurrences.

Notably, in Beynon et al.'s (2016) single-year study for the year 2011, which also examined entrepreneurial attitudes and activity using fsQCA, only 54 countries were included. Here, twice that number of countries are included, with different levels of year-onyear inclusion across the years 2007 to 2017 . The composition of these countries also shows that they are positioned across all five continents, which enables effective comparison of entrepreneurial behavior.

\subsection{Initial calibration}

As part of the preparations for fsQCA analysis, pre-calibration of the considered conditions and outcome is required. This pre-calibration transforms (calibrates) the considered conditions and outcome, originally in their own scales (here, all are given in 
percentages), to fuzzy membership scores ranging from 0 to 1 (see Ragin, 2008, for a full description of this calibration requirement).

The calibration undertaken here follows the direct method described by Ragin (2008), and, more specifically, a developed version outlined by Andrews, Beynon, and McDermott (2016) and Beynon et al. (2016). This developed version uses probability density functions (pdfs) constructed for each condition and outcome. The requirement of the direct method is the establishment of three qualitative anchors for each condition and outcome, which are then used in the log-odds transform to calculate the concomitant degrees of membership values (see Ragin, 2008). These three qualitative anchors identify the lower threshold $-\mathrm{x}^{\perp}\left(5^{\text {th }}\right.$ percentile of constructed pdf), crossover $-\mathrm{x}^{\times}\left(50^{\text {th }}\right.$ percentile of $\left.\mathrm{pdf}\right)$, and upper threshold $-\mathrm{x}^{\mathrm{T}}$ $\left(95^{\text {th }}\right.$ percentile of pdf), which are used to construct the concomitant fuzzy membership score functions, creating the required degrees of membership as scores ranging from 0 to 1 . The established threshold values are then checked by the authors (see Andrews et al., 2016, for an example of this process).

\section{FsQCA analysis}

The initial fsQCA analysis undertaken here follows the standard iterative approach, with both necessity and sufficiency analyses. The sufficiency analysis includes the elucidation of the associated truth table. These analyses are described in the following sections.

\subsection{Necessity analysis}

The analysis of necessary conditions in fsQCA (see Ragin, 2008) is a separate procedure that examines whether individual conditions (there may be more than one) may be necessary or mostly necessary for the outcome to occur. For necessity to hold for a country- 
year observation, the membership score on the outcome must be consistently lower than the membership score of the condition under consideration (see Kent \& Olsen, 2008; see Table 1). Given the asymmetry of fsQCA (Ragin, 2008), results for the two outcomes (High-TEA and Low-TEA) are presented.

Insert Table 1 here.

For the standard threshold of 0.9 (Young \& Park, 2013), the results in Table 1 indicate that no single condition, whether in relation to High-TEA or Low-TEA outcomes, is necessary in the association of cases (country-year observations) to understand TEA.

\subsection{Sufficiency analysis}

The role of subsets of conditions in understanding High-TEA or Low-TEA is considered next in the form of sufficiency analysis (see Ragin, 2008). Sufficiency analysis seeks to find different combinations of conditions that meet specific criteria of sufficiency for the outcome to occur. For sufficiency to hold for a country-year observation, the membership score of the outcome must be consistently higher than the membership score of the combination of conditions (see also Kent \& Olsen, 2008).

Fundamental to this analysis is the truth table, which lists all logically possible combinations of conditions, termed configurations, and the outcome (either High-TEA or Low-TEA). With four conditions considered here, there are $2^{4}=16$ logically possible configurations to consider. The configurations are characterized by 0 and 1 values across the four conditions, where 0 denotes the absence and 1 denotes the presence of each condition. For a country-year observation, the association of a condition's membership score to either 0 or 1 is based on strong membership (depending on whether it is $<=$ or $>0.5$ in value).

Each reported configuration is described by a number of relevant values, including the number of countries associated with each configuration in strong membership and, for 
High-TEA and Low-TEA, the level of consistency measured as the degree to which it can be shown that membership in the outcome is consistently less than or equal to membership in the cause (Ragin, 2008). In terms of which configurations to further consider because of their assured association with either High-TEA or Low-TEA, two further thresholds must be considered. Frequency is the minimum number of country-year observations that must be associated with a configuration for it to be further considered. Consistency is the minimum consistency level for the configuration to be further considered (see Ragin, 2008).

The threshold values were the same for High-TEA and Low-TEA. At least 10 country-year observations were deemed necessary for a configuration to be further considered (see Kraus et al., 2018, for discussion of frequency threshold value and number of cases in data sets). A consistency value above 0.912 was also used (see Andrews et al., 2016) to ensure that no configuration had an association with both High-TEA and Low-TEA in the analyses. In terms of the impact of these threshold value choices, three (with 193 countryyear observations) and nine (with 370 country-year observations) configurations were considered to be associated with High-TEA and Low-TEA, respectively. A total of 563 out of 638 country-year observations were covered by these 12 (out of 16) configurations.

The four configurations that were not further considered are termed remainders (see Ragin, 2008) because of the lack of empirical evidence supporting their association with some outcome (Schneider \& Wagemann, 2012). Although they were not considered to have an association with a specific outcome (High-TEA or Low-TEA), they were discerned in some way in terms of configurations associated with a specific outcome.

Two forms of this discernment are considered here: the complex and parsimonious solutions (see Ragin, 2008; Schneider \& Wagemann, 2010, 2012). There are two reasons for considering these two forms of solutions. First, considering these two solutions is advocated by Wagemann and Schneider (2010), and where no body of existing theory can support the 
inclusion of logical remainders, it might be safer to prioritize complex solutions (Cooper \& Glaesser, 2011). Second, the complex and parsimonious solutions were considered in the original single-year study by Beynon et al. (2016).

For each outcome (High-TEA and Low-TEA), sufficiency analyses were performed to identify combinations of conditions. These combinations are termed causal recipes, and they associate configurations with a specific outcome. The circle notation was adapted from Ragin and Fiss (2008), where $\ominus$ and $\bigcirc$ denote, respectively, absence and presence of a condition, and large and small circles denote, respectively, core and peripheral conditions of the complex and parsimonious solutions (see Table 2).

Insert Table 2 here.

Table 2 shows the results of the sufficiency analysis. For the complex solutions, two (CHT1 and CHT2) and four (CLT1-CLT4) causal recipes were identified to describe HighTEA and Low-TEA, respectively. For the parsimonious solutions, one (PHT1) and four (PLT1-PLT4) causal recipes were identified to describe High-TEA and Low-TEA, respectively.

Comparing these results with those from Beynon et al. (2016) reveals a high degree of similarity in terms of the causal recipes, lending veracity to the earlier results. Specifically, for the complex solutions, one of the two High-TEA recipes (CHT1) is identical in both studies, as are all the Low-TEA recipes (CLT1-CLT4). For the High-TEA recipe that differs (CHT2), Beynon et al. (2016) identified a recipe showing presence of perceived capabilities and entrepreneurial intent and absence of fear of failure. In this longitudinal study, the causal recipe $\mathrm{CHT} 2$ comprises presence of perceived capabilities, entrepreneurial intent, and perceived opportunities. This difference between the two solutions indicates a potential substituting relationship between opportunity and fear of failure, where perceived opportunity is stronger than fear of failure in the long term. To study this finding in more detail, 
examination of the countries covered by these recipes and the stability of these recipes is also required.

\section{Panel data breakdown of fsQCA results}

This section extends the analysis of the previously reported fsQCA results (see Table 4). The goal is to analyze the fsQCA results across the different years and countries by taking advantage of the use of panel data. As discussed previously, this approach employs techniques introduced by Garcia-Castro and Ariño (2016) and Guedes et al. (2016), with brief technical details given later in Appendix B.

Here, three measures, all of which involve consistency formulae, are used to examine various subsets of the country-year data set. The first, POCONS, consists of all observations. This measure therefore corresponds to the already presented consistency values associated with each causal recipe (see Table 2). The second measure, BECONS, consists of specific year observations. The third measure, WICONS, consists of specific country observations. Analyses using BECONS and WICONS are detailed separately for the causal recipes from complex solutions associated with each outcome (High-TEA and Low-TEA).

\subsection{High-TEA}

Table 2 shows two causal recipes (CHT1 and CHT2) associated with High-TEA. Their associated BECONS graphs are shown in Figure 3. For each causal recipe, a BECONS value is calculated for each considered year.

Insert Figure 3 here.

In Figure 3, the BECONS results for $\mathrm{CHT} 1$ and $\mathrm{CHT} 2$ are presented for each individual year included in the data set, irrespective of how many country-year observations 
are associated with each year. The corresponding POCONS values both in numerical terms and as a horizontal dashed line are also shown.

The two BECONS graphs share some similarities. This observation is understandable given the similarities in the causal recipes. For example, in Table 2, configuration 16 is associated with the causal recipes $\mathrm{CHT} 1$ and $\mathrm{CHT} 2$. There is noticeably more repeated consistency in more recent years (2011 onwards; not all years) in BECONS than in POCONS. This finding is consistent with the spread of TEA values across the different years, as shown in Appendix A. Specific years where the BECONS values for CHT1 and CHT2 differ are 2008 (CHT2 > CHT1), 2010 (CHT2 > CHT1), 2011 (CHT1 > CHT2), and 2017 $(\mathrm{CHT} 1>\mathrm{CHT} 2)$. As discussed below, these differences may be related to the reaction to the economic crisis, whereby, particularly in many low-TEA economies, configurations and associated recipes fluctuated before many countries returned to (or approached) the recipes they had previously been associated with pre-crisis.

The WICONS (within consistency) results are at the country level. The consistency results describe how consistent the specific causal recipe is for a given country. This consistency is affected by whether a country is described in strong membership terms with one or more configurations in the years it is present in the data set, discussed later. The relevant WICONS values for all 108 countries are plotted in Figure 4 (for CHT1 and CHT2). ${ }^{1}$ Insert Figure 4 here.

In each graph in Figure 4, the horizontal axis shows countries' WICONS value rank. This rank is ordered for each of the two causal recipes CHT1 (Figure 4a) and CHT2 (Figure 4b), so a different ranking is given each time. The relevant POCONS values are also shown as dashed lines (see Table 2). In each graph, for a given country, two WICONS values are

\footnotetext{
${ }^{1}$ Not all countries have the same number of associated country-year observations in the data set. All are nonetheless included here in this exploratory analysis.
} 
shown (i.e., for CHT1 and CHT2) to enable comparison across causal recipes. The first notable observation is the commencement of inconsistent results (WICONS $<1.000$ within rank-ordered values), which for CHT1 correspond to around 50 countries and for CHT2 correspond to around 60 countries.

The results toward the right of the graphs are the results of interest because they indicate countries that, across the years for which they are included in the 638 country-year observations data set, do not consistently adhere to a specific causal recipe. Broadly, this finding suggests that, for around 60 of the included countries, there is strong consistency. The other countries have different levels of inconsistency across the years for which they are included in the analysis.

\subsection{Low-TEA}

Table 2 shows four causal recipes associated with Low-TEA: CLT1, CLT2, CLT3, and CLT4. Their associated BECONS graphs are shown in Figure 5.

Insert Figure 5 here.

In Figure 5, the BECONS results for CLT1, CLT2, CLT3, and CLT4 are again presented for each individual year included in the data set. The corresponding POCONS values also shown (see Table 2). Again, inspection shows general similarity across the BECONS graphs. This similarity is a consequence of the overlapping inclusion of configurations among the causal recipes considered here. CLT4, which includes the presence of fear of failure, is observed to have a noticeably high consistency from 2010 to 2013. This consistency is then seen to decrease over time to 2017 (as it does for CLT2). This trend is in contrast to the one observed for CLT1 and CLT3, with the exception of the year 2017. 
The WICONS (within consistency) results are at the country level. The relevant WICONS values for the 108 countries in the data set are reported in Figure 6. ${ }^{2}$ As observed earlier, around 60 countries have strong consistency in terms of the recipes with which they are associated. The other countries have different levels of inconsistency across the years for which they are included in the analysis.

Insert Figure 6 here.

As with the analysis for High-TEA, for each of the causal recipes for Low-TEA, there are 40 to 50 countries that have unit WICONS consistency.

\section{Discussion}

This discussion section offers a more country-specific elucidation of the fsQCA results, including causal recipes, BECONS, and WICONS. Overall, the analysis suggests a strong consistency of the relevant causal recipes, reflected by the similarity of these longitudinal results with those reported by Beynon et al. (2016) and the consistency found in the additional BECONS and WICONS analysis of the longitudinal data in this study.

This overall consistency also indicates that, for many countries, the effect of the global economic crisis on entrepreneurial activity was relatively minor, at least according to the recipes identified in this study. However, countries where the association with recipes changed over time also offer an opportunity to explore when recipes changed and how this change is related to the configurations to which those countries are associated. Table 3 reports the strong membership association of a sample of countries to configurations. Without loss of generality, this sample contains all years present in the data set.

\footnotetext{
${ }^{2}$ Not all countries have the same number of associated country-year observations. All are nonetheless included here in this exploratory analysis.
} 
In Table 3, a small sample of countries is considered. For each country and each year represented in the data set, the configurations they are most associated with are noted by year, as well as the causal recipes that then associate that configuration to either High-TEA or Low-TEA. A range of 1 (for Colombia) to 7 (for Croatia) configurations represent the countries shown over the 11 years from 2007 to 2017.

For High-TEA-associated countries, consistency is generally high in the recipes. The global economic crisis appears to have had a minimal effect on entrepreneurial attitudes and activity in these countries. The most relevant High-TEA recipe (CHT1) combines the presence of entrepreneurial opportunities (Prcvd_Opps), capabilities (Prcvd_Caps), and intent (Entrp_Int). For Colombia, there was no change at all in the applicable recipe throughout the entire period, with TEA remaining stable at around 22\%. Chile's TEA also appears to have been strong, remaining around $24 \%$ since 2011 , with strong consistency in the applicable causal recipe (CHT1). Where change is discerned in TEA, this appears to have followed a consistent development pattern that was not strongly affected by the economic crisis. Perhaps most notably, Brazil became associated with one and then both High-TEA recipes over this period. However, at the end of the period under study, Brazil became more associated with a configuration linked to Low-TEA (CLT4: presence of fear of failure and absence of entrepreneurial intent). Broadly speaking, Brazil's TEA also grew in absolute terms over this period.

Low-TEA was primarily, but not exclusively, related to more developed economies. Unsurprisingly, there was not only more complexity in terms of the number of Low-TEAassociated recipes but also fluctuations in these associations over time and more obvious impacts from the 2008 economic crisis. From the examples discussed, CLT1 (absence of opportunity and absence of intent) appears to have been the strongest relevant Low-TEA recipe in the immediate aftermath of the economic crisis. Importantly, however, experiences 
also differed from economy to economy. Comparing four countries that are longstanding members of the European Union throughout this period illustrates this point.

Insert Table 3 here.

Looking at Southern Europe for example, Giannakis and Bruggeman (2017) noted the severe impact of the global financial crisis for peripheral and economically vulnerable countries such as Greece and Spain, where unemployment rates rose steeply because of the enforcement of austerity policies. Beynon et al. (2016) found that Greece was part of a configuration associated with two of the four Low-TEA recipes. Examination of the longitudinal data, however, shows that this situation is likely to be somewhat a result of the global economic crisis: The data show that Greece was associated with all four Low-TEA configurations in 2007, two between 2008 and 2012, and all four again between 2013 and 2017. Spain also followed this pattern for the same recipes, albeit over a slightly different period, dropping to the same two Low-TEA recipes between 2010 and 2012 and then reverting to four between 2013 and 2017. For Spain, this finding might provide support for the hysteresis effect of government policy described by Congregado et al. (2012). Nevertheless, for both Greece and Spain, TEA was lower in 2017 than it was in 2007. Because the change in recipes for the two countries (2008-2012 for Greece and 2010-2012 for Spain) owes to a change in configuration (i.e., the presence of perceived capabilities), this finding may suggest that the reaction of these economies to the economic crisis was to have an increased focus on necessity entrepreneurship, given that no presence of perceived opportunities was identified.

In Northern Europe, Marcotte (2013) identified the UK and the Netherlands as having high overall pre-economic-crisis rankings in entrepreneurial innovation $\left(8^{\text {th }}\right.$ and $9^{\text {th }}$, respectively, out of 21 developed economies). Both of these positions were much higher than Spain's position in $14^{\text {th }}$. The Netherlands saw its TEA rate recover more rapidly than Spain's 
or Greece's. Moreover unlike Spain, the Netherlands (Beynon et al., 2016) was associated with only one Low-TEA recipe (absence of entrepreneurial capabilities and intent). Although the Netherlands did revert back to its 2007 state by 2017, in terms of being associated with the same Low-TEA recipe (absence of perceived entrepreneurial capabilities and absence of entrepreneurial intent), it fluctuated much more around this recipe. In particular, the Netherlands saw the number of Low-TEA recipes it was associated with grow to all four by 2013, before eventually falling to one by 2017. For the Netherlands, the economic crisis can be seen to have initially led to an absence of perceived opportunities. Once perceived opportunities were again present, these were accompanied for several years by a fear of failure, before the configuration reverted to its pre-crisis state (presence of perceived opportunity and absence of fear of failure).

For the UK, the process was even more complicated. Beynon et al.'s (2016) analysis showed an association with all four Low-TEA recipes. This result, however, hides immense fluctuations, from association with three of the Low-TEA recipes prior to the global economic crisis (CLT1, CLT2, CLT3) to just one (CLT1) in the immediate aftermath prior to the change of government and the onset of austerity measures. All four Low-TEA recipes then applied between 2011 and 2014, before falling to two from 2015 to 2017. Although the UK was associated with CLT1 prior to the economic crisis, it was not associated with CLT4 (presence of fear of failure and absence of entrepreneurial intent) prior to 2011. In terms of configurations, the changes in recipes can be seen to be related to a short-lived presence of perceived capabilities between 2008 and 2010, which might suggest increased necessity entrepreneurship, later becoming absent again. This period was followed by a period with a consistent presence of fear of failure from 2011 onwards. After 2015, the presence of perceived opportunities caused a further change in the associated recipes. The fact that from 2015 its configuration included both presence of opportunity and presence of fear of failure 
may be related to effects before and after the Brexit referendum, which may have generated additional uncertainty. In addition, although the UK TEA rate recovered relatively quickly after the economic crisis, it was lower in 2017 than it had been in 2012.

For newer members of the EU, Slovenia and Croatia, as well as the USA, the reaction to the economic crisis manifested itself in a fall in TEA in the initial post-economic-crisis period (2008-2011), followed by a rise in TEA to a level that, by 2017, was greater than in 2007. For Slovenia, the relevant recipe essentially changed from CLT2 (opportunities present and capabilities absent) to CLT1 (opportunities absent and capabilities present). For Croatia, the most relevant recipe essentially reverted to CLT1, with which it was first associated in 2009 and again from 2015 onwards. CLT3 (absence of opportunities and absence of capabilities) was the recipe that Croatia was associated with between 2011 and 2014. For both these countries, however, association with CLT1 would suggest a greater reliance on necessity entrepreneurship. Like in other countries, in the USA in the initial period after the economic crisis, the dominant recipe became CLT1. From 2012 onwards, however, Croatia's configuration included the presence of both opportunities and capabilities, which, although not associated with any causal recipes, does suggest a resilient reaction to the economic crisis, particularly given that neither of these conditions had been present in 2007. This finding also supports the lack of a hysteresis effect found by Congregado et al. (2012). Indeed, this finding suggests that the USA in many ways lies between High-TEA and LowTEA outcomes.

Perhaps most interestingly, Uruguay moved from being associated with a Low-TEA recipe (CLT1) before the economic crisis in 2007 to being associated with High-TEA recipes, particularly CHT1, after the economic crisis (2009-2014). However, at the end of the period under study, Uruguay was not associated with any causal recipe as its configuration moved back toward that seen in 2007. Uruguay's TEA also changed from around 12\% in 2007 and 
an average of $12 \%$ in the 2007 to 2010 period, to nearly $17 \%$ in 2011 and an average of more than $15 \%$ between 2011 and 2014, before falling to $14 \%$ after 2014 .

\section{Conclusions}

This study offers a country-level understanding of entrepreneurial activity and attitudes based on a novel approach using a panel data set and fsQCA. The study builds on previous research (Beynon et al., 2016) based on only single-year analysis for 2011. This 11year longitudinal study (2007-2017) provides a robust discussion of the trends and evolution of entrepreneurial attitudes and activity over this period. Thus, the study offers several contributions.

First, with respect to fsQCA, this study compares results from a single year with multiyear panel data. The fsQCA results, in terms of causal recipes, are similar to those found in the single-year study for 2011. In both cases, the same variables were used. The data set of 638 country-year observations from 108 countries also displays robustness versus the 54 country-year observations for 2011 used by Beynon et al. (2016). The panel data analysis, following the development of panel data fsQCA (Garcia-Castro and Ariño, 2016), also suggests that this method offers a promising approach to "longitudinal set-theoretic research," as previously stated. The technical BECONS and WICONS consistency measures offer nuances at the year and country levels, with the interpretation of findings supporting this point.

Second, this study offers novel insights into the stability of GEM data as a mechanism to effectively gauge entrepreneurial attitudes and activity. Specifically, although the applicable recipes themselves are relatively stable, there are fluctuations in the recipes associated with given countries, particularly innovation-driven economies with Low-TEA 
outcomes, in relation to the aftermath of the 2008 economic crisis. These fluctuations occur to different degrees in terms of timespan and changes in countries' associated recipes.

Third, the study highlights the heterogeneous experiences of developing and developed economies as groups as well as individual economies following the 2008 economic crisis in relation to changes in TEA and associated causal recipes. This analysis suggests that policy differences between countries may help explain these differences and may require further investigation. It also identifies the countries that are most relevant for further study, depending on the evolution of entrepreneurial behaviour. The USA is an example of a country with a seemingly robust and resilient response to the economic crisis, whereas the UK's more nuanced experience also seems in need of further evaluation, potentially in comparison to other EU countries such as the Netherlands. In addition, the contrast between Brazil's and Uruguay's experiences and the explanations for this contrast also seem worthy of further research.

There are limitations to this study. For example, GEM individual country data sets do not consistently appear in all surveys for a variety of reasons. This study also fails to explore why the recipes and configurations changed in particular countries and how these changes might be related to changing policies, again highlighting a need for further study.

This study does, however, show that fsQCA can be used to evaluate individual country-level entrepreneurial performance over a long period, potentially offering valuable future insight for policymakers regarding the effectiveness of entrepreneurial initiatives and trend analysis. The novelty of the study in terms of the longitudinal analysis, which can be contrasted with previous single-year analysis (Beynon et al., 2016), enables the dynamic nature of entrepreneurial activity to be evaluated in a way that was not previously possible. The policy and managerial implications of the results are numerous. For GEM, this study highlights the importance of regular updates to the data set across as many countries as 
possible. For governments, particularly in innovation-driven economies, the study indicates a need for constant review of the conditions and supporting policies that drive entrepreneurship and entrepreneurial activities themselves, given the fluctuations that are likely to be caused by economic shocks. 


\section{Appendix A}

This appendix describes the membership score values cohorted by year (see Figures $\mathrm{A} 1$ and $\mathrm{A} 2)$.

a) Prcvd_Opps $(F(1,636)=3.5, p=.062)$

b) Prcvd_Caps $(F(1,636)=0.35, p=.55)$

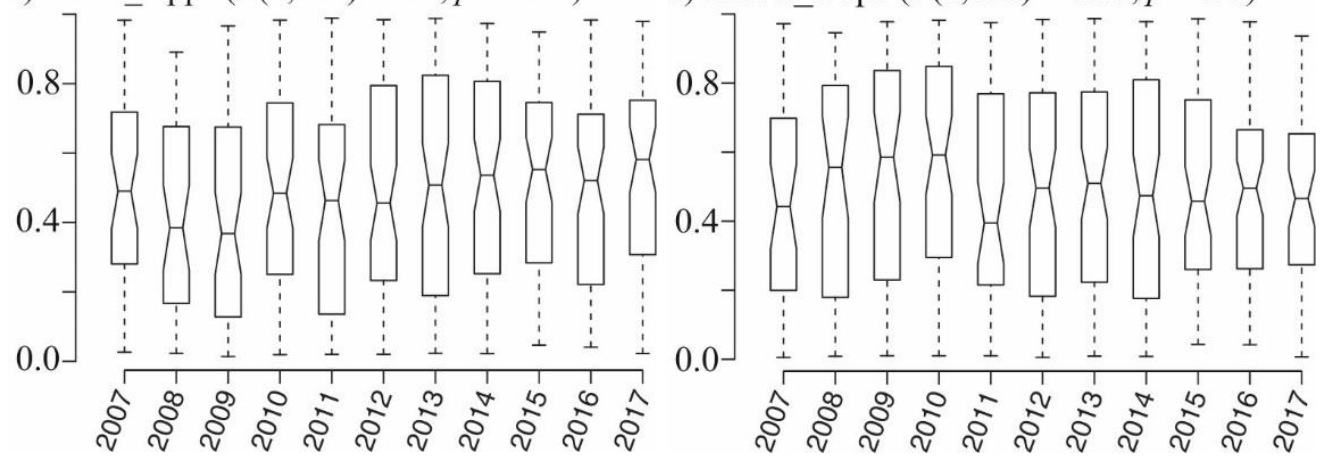

c) Fr_of_Flr $(F(1,636)=10.3, p=.001)$

d) Entrp_Intnt $(F(1,636)=10, p=.002)$

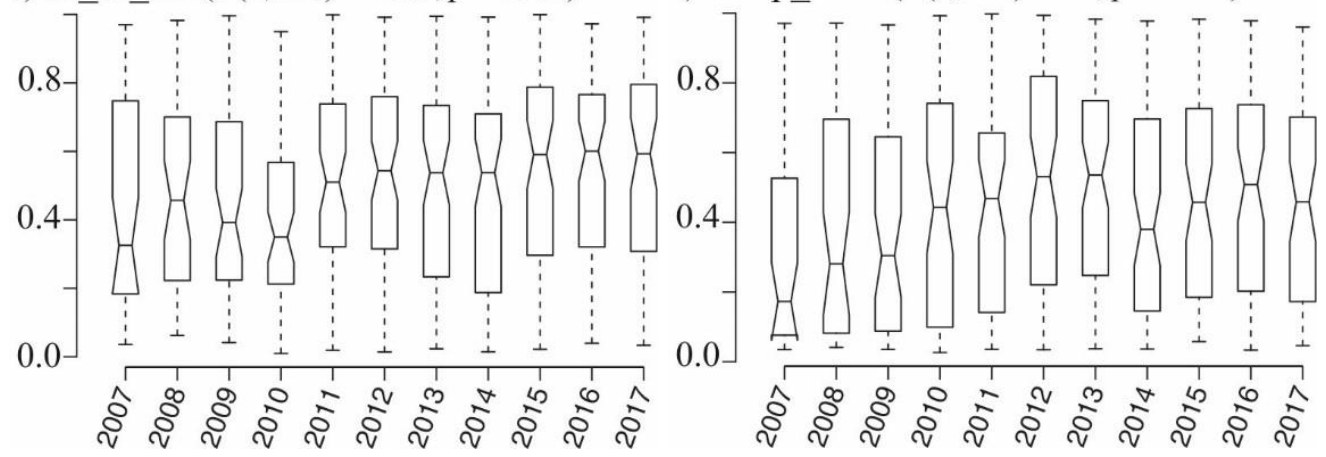

Figure A1:

Boxplot-based breakdown of conditions' membership score

a) $\operatorname{TEA}(F(1,636)=18.2, p=.000)$

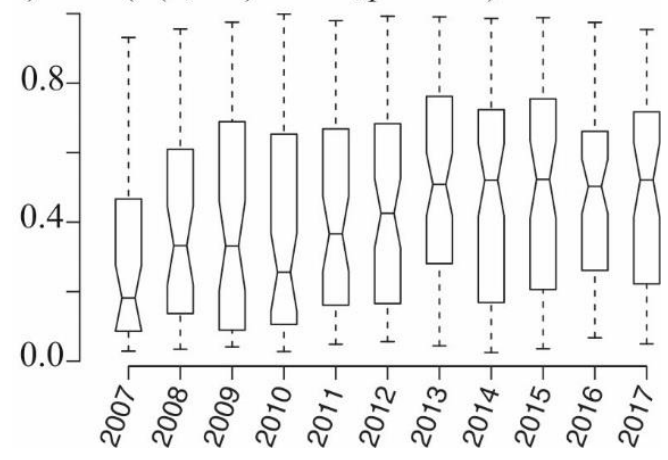

Figure A2:

Boxplot-based breakdown of outcomes' membership score 
In Figures A1 and A2, the conditions and outcome membership scores for the 638 country-year observations are cohorted by year and expressed using notched box plots. 


\section{Appendix B}

This Appendix describes the technical details in regard to the fsQCA consistency formulae employed here, including the concomitant panel data developments. The majority of the details are taken from Garcia-Castro and Ariño (2016).

Ragin (2008) uses a standard measure of set-theoretic consistency, or the degree of inclusion between two sets (set-subset relationship). Note that a fuzzy-subset relation exists when the membership scores in one set are consistently less than or equal to their corresponding membership scores in another. This measure is given by

Consistency $\left(X_{i} \leq Y_{i}\right)=\frac{\sum_{i=1}^{N} \min \left(X_{i}, Y_{i}\right)}{\sum_{i=1}^{N} X_{i}}$,

where $\mathrm{X}_{\mathrm{i}}$ is the degree of membership of individual $\mathrm{i}$ in set $\mathrm{X}$, and $\mathrm{Y}_{\mathrm{i}}$ is its degree of membership in set $\mathrm{Y}$.

For panel data analysis using fsQCA, there are still $\mathrm{N}$ cases, but now over T years, so Pooled consistency (POCONS) is defined as follows:

POCONS: Pooled Consistency $\left(\mathrm{X}_{\mathrm{it}} \leq \mathrm{Y}_{\mathrm{it}}\right)=\frac{\sum_{\mathrm{i}=1}^{\mathrm{N}} \sum_{\mathrm{t}=1}^{\mathrm{T}} \min \left(\mathrm{X}_{\mathrm{it}}, \mathrm{Y}_{\mathrm{it}}\right)}{\sum_{\mathrm{i}=1}^{N} \sum_{\mathrm{t}=1}^{\top} \mathrm{X}_{\mathrm{it}}}$,

where $\mathrm{X}_{\mathrm{it}}$ is the degree of membership of individual $\mathrm{i}$ in time $\mathrm{t}$ in set $\mathrm{X}$, and $\mathrm{Y}_{\text {it }}$ is its degree of membership in set Y. In some sense, this measure is the same as Consistency if not considering the time element.

Alternatively, the consistency for each single year $t$ in the panel is given by

BECONS: Between Consistency $\left(X_{i t} \leq Y_{i t}\right)=\frac{\sum_{i=1}^{N} \min \left(X_{i t}, Y_{i t}\right)}{\sum_{i=1}^{N} X_{i t}}$, for each $t=1, \ldots, T$.

It is also possible to measure whether the "subsetness" connection between $\mathrm{X}_{\mathrm{it}}$ and $\mathrm{Y}_{\mathrm{it}}$ is consistent over time: 
WICONS: Within Consistency $\left(X_{i t} \leq Y_{i t}\right)=\frac{\sum_{t=1}^{\top} \min \left(X_{i t}, Y_{i t}\right)}{\sum_{t=1}^{\top} X_{i t}}$, for each $i=1, \ldots, N$. 


\section{References}

Ács, Z. (2006). How is Entrepreneurship Good for Economic Growth. Innovations, 1(1), 97107.

Ács, Z. J., Desai, S., \& Hessels, J. (2008). Entrepreneurship, economic development and institutions. Small Business Economics, 31(3), 219-234.

Ács, Z. J., \& Szerb, L. (2007). Entrepreneurship, economic growth and public policy. Small Business Economics, 28(2-3), 109-122.

Andrews, R., Beynon, M. J., \& McDermott, A. M. (2016). Organizational capability in the public sector: a configurational approach. Journal of Public Administration Research and Theory, 26(2), 239-258.

Anwar ul Haq, M., Usman, M., Hussain, N., \& Anjum, Z. U. Z. (2014). Entrepreneurial activity in China and Pakistan: A GEM data evidence. Journal of Entrepreneurship in Emerging Economies, 6(2), 179-193.

Arenius, P. and Minniti, M. (2005). Perceptual variables and nascent entrepreneurship. Small Business Economics, 24(3), 233-247.

Autio, E., Keeley, R., Klofsten, M., Parker, G., \& Hay, M. (2001). Entrepreneurial Intent among Students in Scandinavia and in the USA. Enterprise and Innovation Management Studies, 2(2), 145-160.

Baumol, W.J., Litan, R.E., \& Schramm, C.J. (2009). Good capitalism, bad capitalism, and the economics of growth and prosperity. New Haven, CT: Yale University Press.

Beynon, M. J., Jones, P., \& Pickernell, D. (2016). Country-based comparison analysis using fsQCA investigating entrepreneurial attitudes and activity. Journal of Business Research, 69(4), 1271-1276. 
Beynon, M. J., Jones, P., \& Pickernell, D. (2018). Entrepreneurial climate and selfperceptions about entrepreneurship: a country comparison using fsQCA with dual outcomes. Journal of Business Research, 89, 418-428.

Bosma, N., \& Schutjens, V. (2011). Understanding regional variation in entrepreneurial activity and entrepreneurial attitude in Europe. Annals of Regional Science, 47(3), $711-742$.

Bosma, N., Wennekers, S., \& Amorós, J. E. (2012). Global Entrepreneurship Monitor, 2011 Extended Report: Entrepreneurs and Entrepreneurial Employees Across the Globe, Global Entrepreneurship Research Association. Retrieved from http://gemconsortium.org/report, Accessed date $1^{\text {st }}$ July 2018.

Braver, L., \& Danneels, E. (2018). Propensities Return us to the Discovery-Creation Debate about entrepreneurial opportunities. Academy of Management Review, 43(4), 812818.

Burton, M. D., Sørensen, J. B., \& Dobrev, S. D. (2016). A careers perspective on entrepreneurship. Entrepreneurship Theory and Practice, 40(2), 237-247.

Congregado, E., Golpe, A. A., \& Parker, S. C. (2012). The dynamics of entrepreneurship: hysteresis, business cycles and government policy. Empirical Economics, 43(3), $1239-1261$.

Cooper, B., \& Glaesser, J. (2011). Paradoxes and pitfalls in using Fuzzy Set QCA: Illustrations from a critical review of a study of educational inequality. Sociological Research Online, 16(3), 1-14.

Cui, Y., Sun, C., Xiao, H., \& Zhao, C. (2016). How to become an excellent entrepreneur: The moderating effect of risk propensity on alertness to business ideas and entrepreneurial capabilities. Technological Forecasting and Social Change, 112, 171-177. 
Davidsson, P. (2015). Entrepreneurial opportunities and the entrepreneurship nexus: A reconceptualization. Journal of Business Venturing, 30(5), 674-695.

Garcia-Castro, R., \& Ariño, M. A. (2016). A general approach to panel data set-theoretic research. Journal of Advances in Management Sciences \& Information Systems, 2, $63-76$.

Giannakis, E., \& Bruggeman, A. (2017). Economic crisis and regional resilience: Evidence from Greece. Papers in Regional Science, 96(3), 451-476.

GEM. (2019). Entrepreneurial Behaviour and Attitudes. Retrieved from https://www.gemconsortium.org/about/gem. Accessed date 1st July 2018.

Guedes, M. J., da Conceição Gonçalves, V., Soares, N., \& Valente, M. (2016). UK evidence for the determinants of R\&D intensity from a panel fsQCA. Journal of Business Research, 69(11), 5431-5436.

Gundry, L. K., \& Welsch, H. (2001). The ambitious entrepreneur: High growth strategies of women-owned enterprises. Journal of Business Venturing, 16(5), 453-470.

Gupta, V. K., Guo, C., Canever, M., Yim, H. R., Sraw, G. K., \& Liu, M. (2014). Institutional environment for entrepreneurship in rapidly emerging major economies: the case of Brazil, China, India, and Korea. International Entrepreneurship and Management Journal, 10(2), 367-384.

Hindle, K. (2006). A measurement framework for international entrepreneurship policy research: From impossible index to malleable matrix. International Journal of Entrepreneurship and Small Business, 3(2), 139-182.

IMF. (2009). World Economic Outlook: Crisis and Recovery, April. Retrieved from: http://www.imf.org/external/pubs/ft/weo/2009/01/pdf/text.pdf. Accessed date January 25th, 2019. 
Karra, N., Phillips, N., \& Tracey, P. (2008). Building the born global firm: developing entrepreneurial capabilities for international new venture success. Long Range Planning, 41(4), 440-458.

Kelley, D., Singer, S., \& Herrington, M. (2015). Global Entrepreneurship Monitor 2015/16 Global Report. Retrieved from http://www.gemconsortium.org/report. Accessed date 2nd August 2019.

Kent, R., \& Olsen, W. (2008). Using fsQCA a Brief Guide and Workshop for Fuzzy-Set Qualitative Comparative Analysis. Retrieved from http://hummedia.manchester.ac.uk/institutes/cmist/archive-publications/workingpapers/2008/2008-10-teaching-paper-fsqca.pdf. Accessed date 15th September 2019.

Kibler, E., Kautonen, T., \& Fink, M. (2014). Regional social legitimacy of entrepreneurship: Implications for entrepreneurial intention and start-up behaviour. Regional Studies, 48(6), 995-1015.

Kraus, S., Ribeiro-Soriano, D., \& Schüssler, M. (2018). Fuzzy-set qualitative comparative analysis (fsQCA) in entrepreneurship and innovation research-the rise of a method. International Entrepreneurship and Management Journal, 14(1), 15-33.

Manolova, T. S., Eunni, R. V., \& Gyoshev, B. S. (2008). Institutional environments for entrepreneurship: Evidence from emerging economies in Eastern Europe. Entrepreneurship Theory and Practice, 32(1), 203-218.

Marcotte, C. (2013). Measuring entrepreneurship at the country level: a review and research agenda. Entrepreneurship and Regional Development, 25(3/4), 174-194.

McGee, J. E., Peterson, M., Mueller, S. L., \& Sequeira, J. M. (2009). Entrepreneurial self efficacy: Refining the measure. Entrepreneurship Theory and Practice, 33(4), 965988. 
Misangyi, V. F., Greckhamer, T., Furnari, S., Fiss, P. C., Crilly, D., \& Aguilera, R. (2017). Embracing causal complexity: The emergence of a neo-configurational perspective. Journal of Management, 43(1), 255-282.

Nyström, K. (2012). Entrepreneurial employees: Are they different from independent entrepreneurs? CESIS Electronic Working Paper Series, No. 281.

Ragin, C. C. (2008). Redesigning social inquiry: Fuzzy sets and beyond. Chicago, IL: University of Chicago Press. 2008.

Ragin, C. C., \& Fiss, P. (2008). Net effects versus configurations: An empirical demonstration. In C. C. Ragin (Ed.), Redesigning social inquiry: Fuzzy sets and beyond (pp. 190-212). Chicago, IL: University of Chicago Press.

Roig-Tierno, N., Huarng, K. H., \& Ribeiro-Soriano, D. (2016). Qualitative comparative analysis: Crisp and fuzzy sets in business and management. Journal of Business Research, 69(4), 1261-1264.

Roper, S., \& Scott, J. M. (2009). Perceived financial barriers and the start-up decision: An econometric analysis of gender differences using GEM data. International Small Business Journal, 27(2), 149-171.

Schneider, C. Q. \& Wagemann, C. (2010). Standards of good practice in Qualitative Comparative Analysis (QCA) and fuzzy-sets. Comparative Sociology, 9, 397-418.

Schneider, C. Q., \& Wagemann, C. (2012). Set-theoretic methods for the social sciences: A guide to qualitative comparative analysis. Cambridge: Cambridge University Press.

Souitaris, V., Zerbinati, S., \& Al-Laham, A. (2007). Do entrepreneurship programmes raise entrepreneurial intention of science and engineering students? The effect of learning, inspiration and resources. Journal of Business Venturing, 22(4), 566-591.

Uhlaner, L., \& Thurik, R. (2007). Postmaterialism influencing total entrepreneurial activity across nations. Journal of Evolutionary Economics, 17(2), 161-185. 
Urbano, D., Aparicio, S., \& Audretsch, D. (2018). Twenty-five years of research on institutions, entrepreneurship, and economic growth: what has been learned? Small Business Economics, 53(1), 21-49.

Vaillant, Y., \& Lafuente, E. (2007). Do different institutional frameworks condition the influence of local fear of failure and entrepreneurial examples over entrepreneurial activity? Entrepreneurship \& Regional Development, 19(4), 313-337.

Van Stel, A., Carree, M., \& Thurik, R. (2005). The effect of entrepreneurial activity on national economic growth. Small Business Economics, 24(3), 311-321.

Wagemann, C., \& Schneider. C. Q. (2010). Qualitative comparative analysis (ACA) and fuzzy-sets: Agenda for a research approach and a data analysis technique. Comparative Sociology, 9(3), 376-96.

Wennekers, S., van Stel, A., Thurik, R., \& Reynolds, P. (2005). Nascent entrepreneurship and the level of economic development. Small Business Economics, 24(3), 293-309.

Wong, P. K., Ho, Y. P., \& Autio, E., (2005). Entrepreneurship, innovation and economic growth: evidence from GEM data. Small Business Economics, 24(3), 335-350.

Wyrwich, M., Stuetzer, M., \& Sternberg, R. (2016). Entrepreneurial role models, fear of failure, and institutional approval of entrepreneurship: A tale of two regions. Small Business Economics, 46(3), 467-492.

Young, K. L., \& Park, S. H. (2013). Regulatory opportunism: Cross-national patterns in national banking regulatory responses following the global financial crisis, Public Administration, 91(3), 561-581. 
Table 1:

Analysis of necessity for TEA (High-TEA and Low-TEA)

\begin{tabular}{cccccc}
\hline \multirow{2}{*}{ Condition } & \multicolumn{4}{c}{ Outcome - TEA } \\
& \multicolumn{4}{c}{ High-TEA } & $\begin{array}{c}\text { Low-TEA } \\
\text { Consistency Coverage }\end{array}$ \\
\hline \multirow{2}{*}{ Prcvd_Opps } & High & 0.824 & 0.746 & 0.533 & 0.602 \\
& Low & 0.560 & 0.490 & 0.775 & 0.846 \\
Prcvd_Caps & High & 0.863 & 0.769 & 0.523 & 0.582 \\
& Low & 0.531 & 0.471 & 0.792 & 0.878 \\
\multirow{5}{*}{ Fr_of_Flr } & High & 0.608 & 0.546 & 0.703 & 0.787 \\
& Low & 0.763 & 0.673 & 0.595 & 0.655 \\
Entrp_Intnt & High & 0.832 & 0.828 & 0.450 & 0.560 \\
& Low & 0.557 & 0.448 & 0.862 & 0.865 \\
Statistics & Min & 0.531 & 0.448 & 0.450 & 0.560 \\
& Max & 0.863 & 0.828 & 0.862 & 0.878 \\
\hline
\end{tabular}


Table 2:

Sufficiency analysis of Prcvd_Opps, Prcvd_Caps, Fr_of_Flr, and Entrp_Intnt conditions with High-TEA and Low-TEA outcomes

\begin{tabular}{|c|c|c|c|c|c|}
\hline \multirow{3}{*}{$\begin{array}{l}\text { Conditions } \\
\text { Prcvd_Opps }\end{array}$} & \multicolumn{5}{|c|}{ TEA } \\
\hline & \multicolumn{2}{|l|}{ High } & \multicolumn{2}{|c|}{ Low } & \\
\hline & & $\theta$ & & $\theta$ & \\
\hline Prcvd_Caps & • & & $\theta$ & $\ominus$ & \\
\hline Fr_of_Flr & 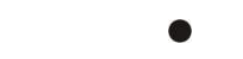 & & & & \\
\hline Entrp_Int & & $\theta$ & $\ominus$ & & $\ominus$ \\
\hline Complex Solution & CHT1 CHT2 & CLT1 & CLT2 & CLT3 & CLT4 \\
\hline $\begin{array}{c}\text { Configurations (in strong membership } \\
\text { terms) }\end{array}$ & $14,1612,16$ & $\begin{array}{l}1,3,5 \\
7\end{array}$ & $\begin{array}{c}1,3,9 \\
11\end{array}$ & $\begin{array}{c}1,2,3 \\
4\end{array}$ & $\begin{array}{l}3,7,11, \\
15\end{array}$ \\
\hline Consistency* & 0.9200 .907 & 0.935 & 0.938 & 0.923 & 0.919 \\
\hline Raw Coverage* & 0.6760 .433 & 0.699 & 0.736 & 0.658 & 0.631 \\
\hline Unique Coverage* & 0.2760 .032 & 0.051 & 0.050 & 0.041 & 0.011 \\
\hline Solution Consistency* & 0.909 & & & 83 & \\
\hline Solution Coverage* & 0.709 & & & 70 & \\
\hline Parsimonious Solution & PHT1 & PLT1 & PLT2 & PLT3 & PLT4 \\
\hline $\begin{array}{c}\text { Configurations (in strong membership } \\
\text { terms) }\end{array}$ & $12,14,16$ & $\begin{array}{c}1,3,5 \\
7\end{array}$ & $\begin{array}{l}1,3,9 \\
11\end{array}$ & $\begin{array}{c}1,2,3 \\
4\end{array}$ & $\begin{array}{l}3,7,11, \\
15\end{array}$ \\
\hline Consistency* & 0.903 & 0.935 & 0.938 & 0.923 & 0.919 \\
\hline Raw Coverage* & 0.716 & 0.699 & 0.736 & 0.658 & 0.631 \\
\hline Unique Coverage* & 0.716 & 0.051 & 0.050 & 0.041 & 0.011 \\
\hline Solution Consistency* & 0.903 & & & 83 & \\
\hline Solution Coverage* & 0.716 & & & 70 & \\
\hline
\end{tabular}

Note: $*$ The consistency and coverage values are over the whole data set of cases (not just from those configurations shown associated in strong membership terms). 
Table 3:

Breakdown of country-specific strong membership to configurations (2007-2017) [Prcvd_Opps, Prcvd_Caps, Fr_of_Flr, Entrp_Intnt]

\begin{tabular}{|c|c|c|c|c|c|c|c|c|}
\hline Country & Strong membe & ip details & & & & & & \\
\hline \multirow{3}{*}{ Brazil } & Configuration & {$[0,1,0,1]$} & {$[0,1,1,1]$} & {$[1,1,0,1]$} & {$[1,1,1,1]$} & {$[1,1,1,0]$} & & \\
\hline & Years & 2007 & 2008,2016 & $\begin{array}{l}2009,2010,2011, \\
2012,\end{array}$ & $2013,2014,2015$ & 2017 & & \\
\hline & $\begin{array}{l}\text { Causal } \\
\text { recipe(s) }\end{array}$ & --- & --- & CHT1 & CHT1|CHT2 & CLT4 & & \\
\hline \multirow{3}{*}{ Chile } & Configuration & $\begin{array}{l}{[1,1,0,1]} \\
2007,2009,2010,2011,\end{array}$ & {$[0,1,0,1]$} & & & & & \\
\hline & Years & $\begin{array}{l}2012,2013,2014,2015 \\
2016,2017\end{array}$ & 2008 & & & & & \\
\hline & $\begin{array}{l}\text { Causal } \\
\text { recipe(s) }\end{array}$ & CHT1 & --- & & & & & \\
\hline \multirow{3}{*}{ Colombia } & Configuration & {$[1,1,0,1]$} & & & & & & \\
\hline & Years & $\begin{array}{l}\text { 2007, 2008, 2009, 2010, } \\
2011,2012,2013,2014 \\
2015,2016,2017\end{array}$ & & & & & & \\
\hline & $\begin{array}{l}\text { Causal } \\
\text { recipe(s) }\end{array}$ & CHT1 & & & & & & \\
\hline \multirow{3}{*}{ Croatia } & Configuration & {$[1,1,0,0]$} & {$[0,1,1,0]$} & {$[0,1,0,0]$} & {$[0,0,0,1]$} & {$[0,0,1,1]$} & {$[0,0,1,0]$} & {$[0,1,1,1]$} \\
\hline & Years & 2007,2008 & 2009 & 2010,2017 & 2011,2014 & 2012,2013 & 2015 & 2016 \\
\hline & $\begin{array}{l}\text { Causal } \\
\text { recipe(s) }\end{array}$ & --- & CLT1|CLT4 & CLT1 & CLT3 & CLT3 & $\begin{array}{l}\text { CLT1|CLT2| } \\
\text { CLT3|CLT4 }\end{array}$ & --- \\
\hline \multirow{3}{*}{ Greece } & Configuration & {$[0,0,1,0]$} & {$[0,1,1,0]$} & & & & & \\
\hline & Years & $\begin{array}{l}2007,2011,2013,2014, \\
2015,2016,2017\end{array}$ & $\begin{array}{l}2008,2009 \\
2010,2012\end{array}$ & & & & & \\
\hline & $\begin{array}{l}\text { Causal } \\
\text { recipe(s) }\end{array}$ & $\begin{array}{l}\text { CLT1|CLT2| } \\
\text { CLT3|CLT4 }\end{array}$ & CLT1|CLT4 & & & & & \\
\hline Netherlands & Configuration & {$[1,0,0,0]$} & {$[0,0,0,0]$} & {$[1,0,1,0]$} & {$[0,0,1,0]$} & & & \\
\hline
\end{tabular}




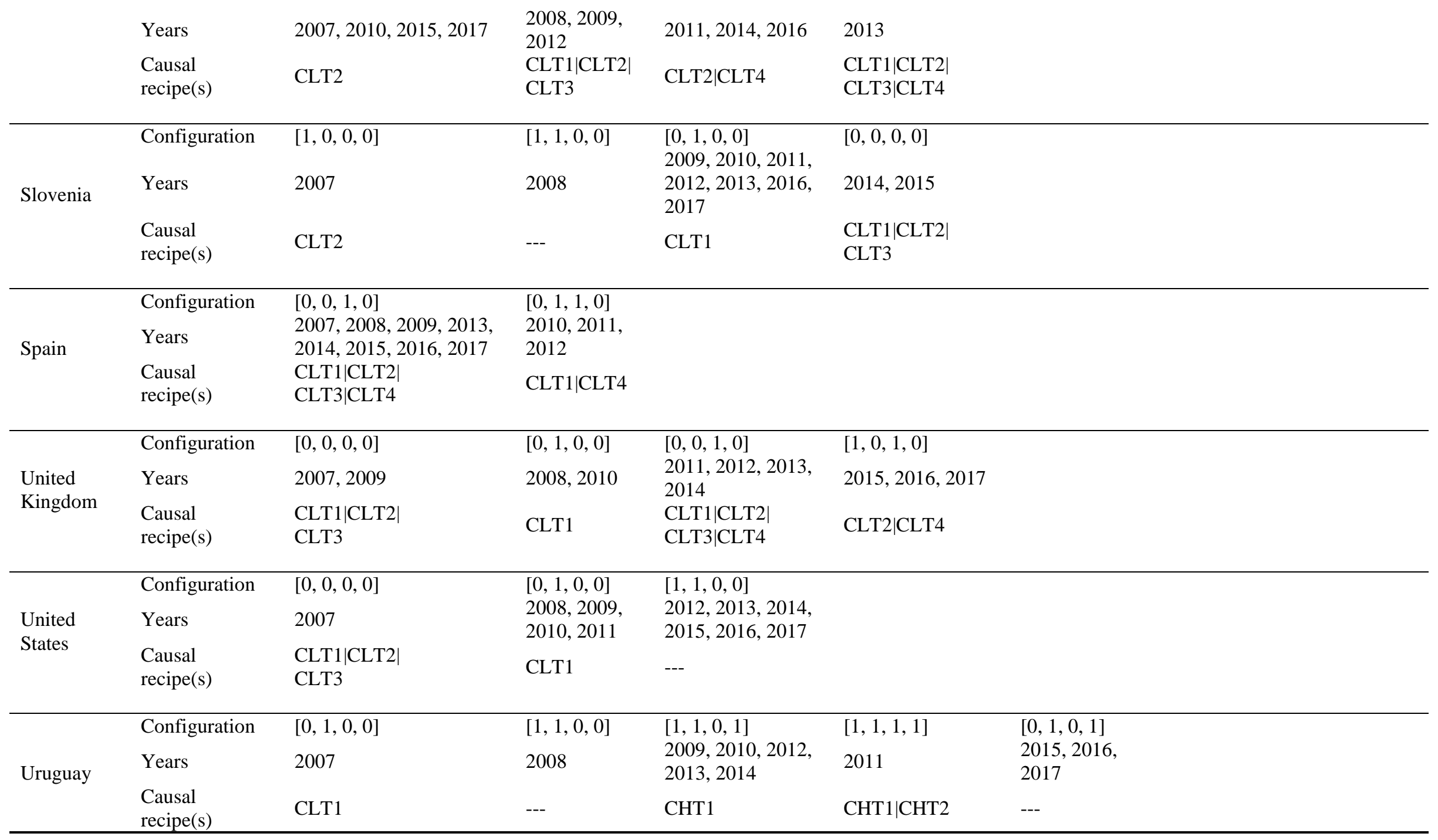




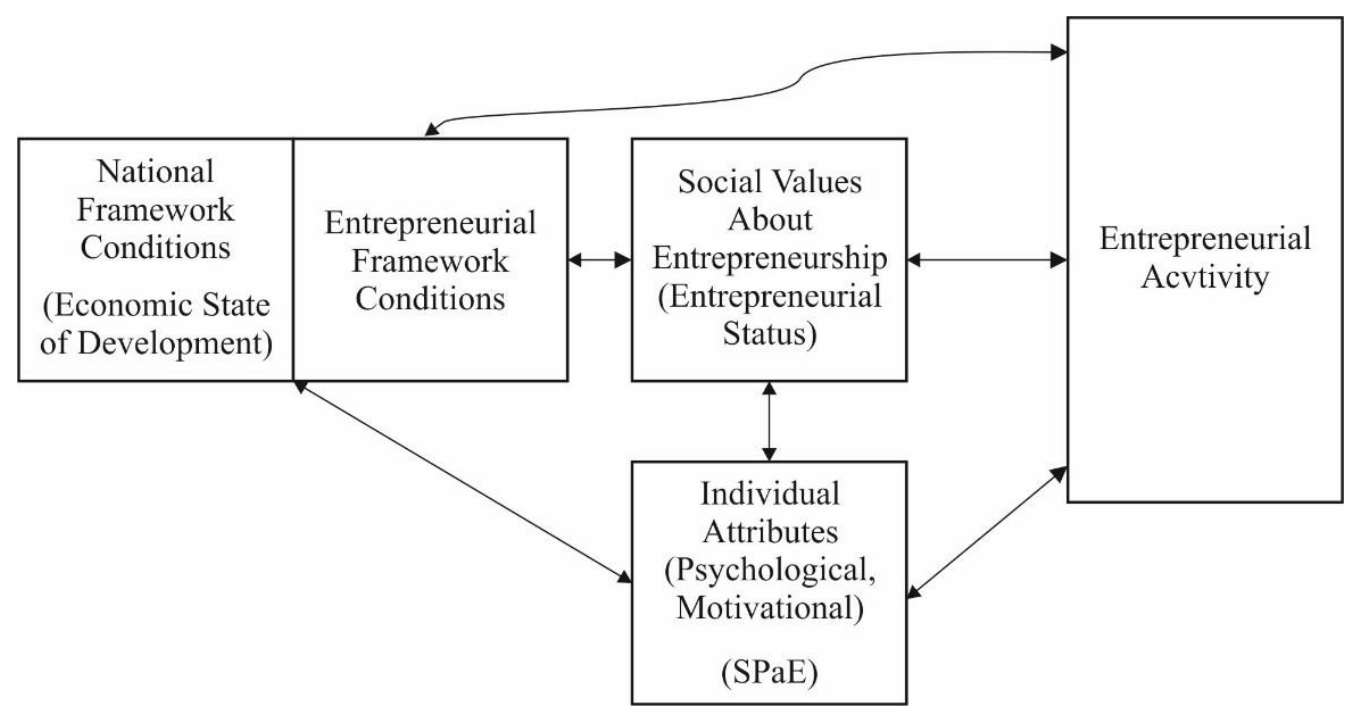

Figure 1:

\section{GEM conceptual framework}

Source: Beynon et al. (2018) 


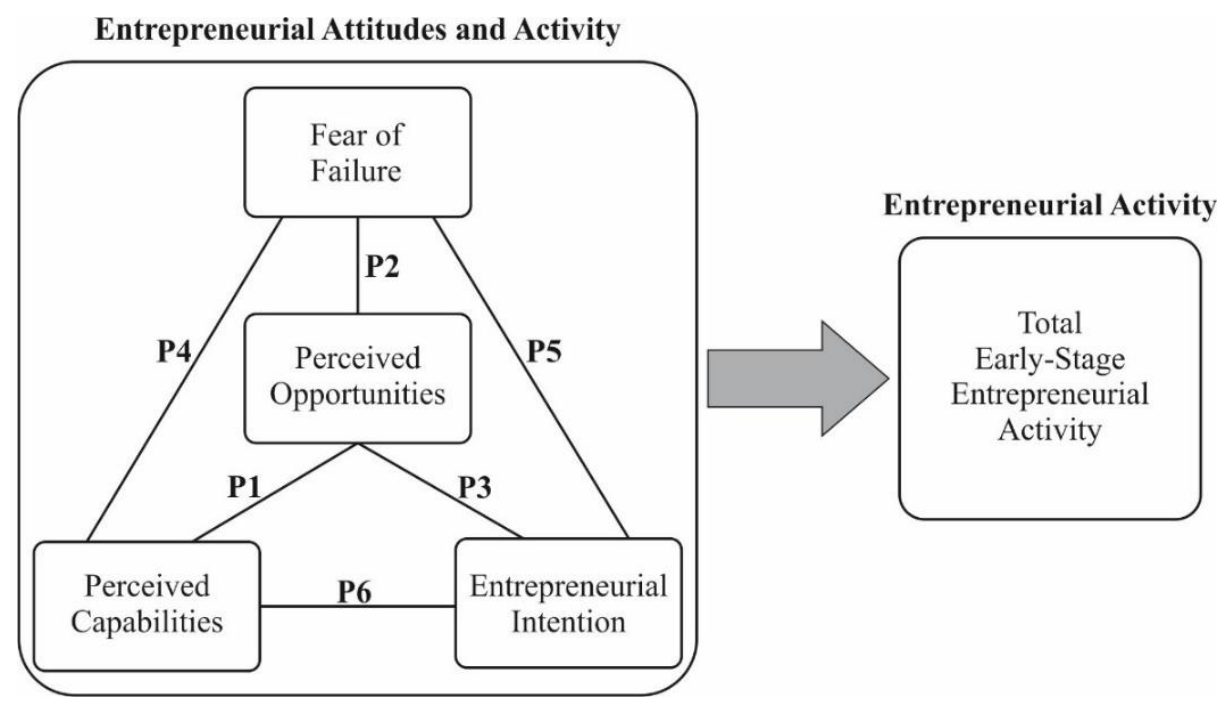

Figure 2:

\section{Conceptual framework}




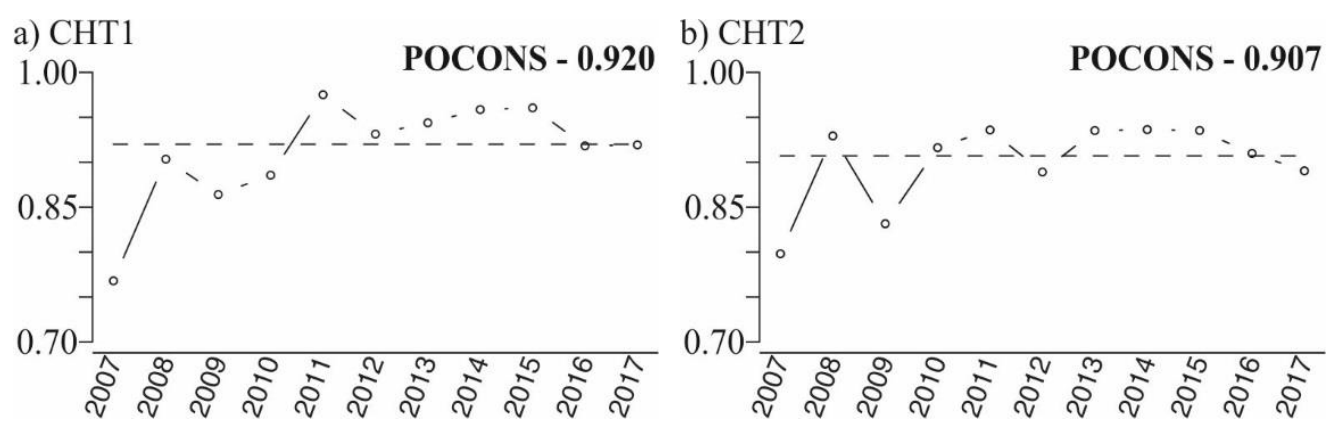

Figure 3:

BECONS values (2007-2017) for causal recipes CHT1 and CHT2 (High-TEA outcome) 


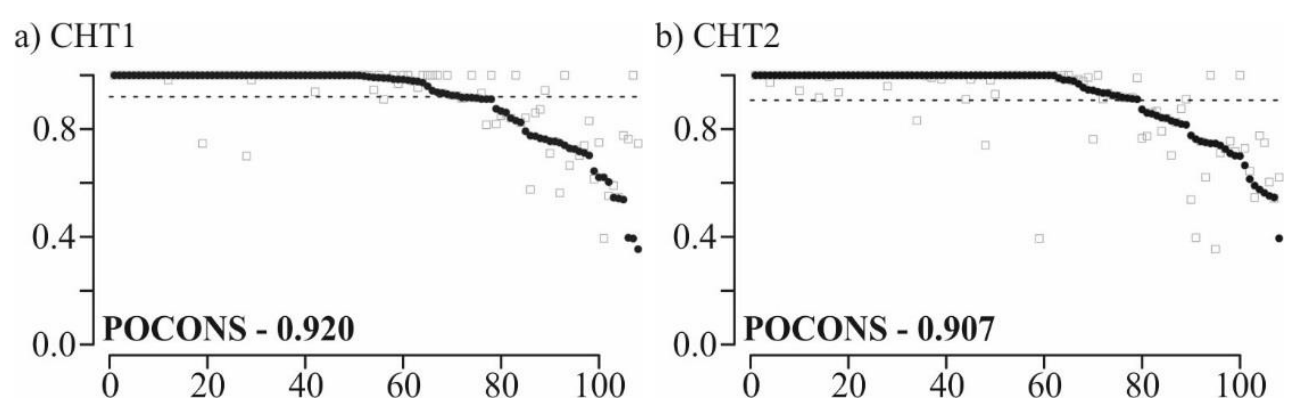

Figure 4:

WICONS values for all countries for causal recipes CHT1 and CHT2 (High-TEA outcome) 

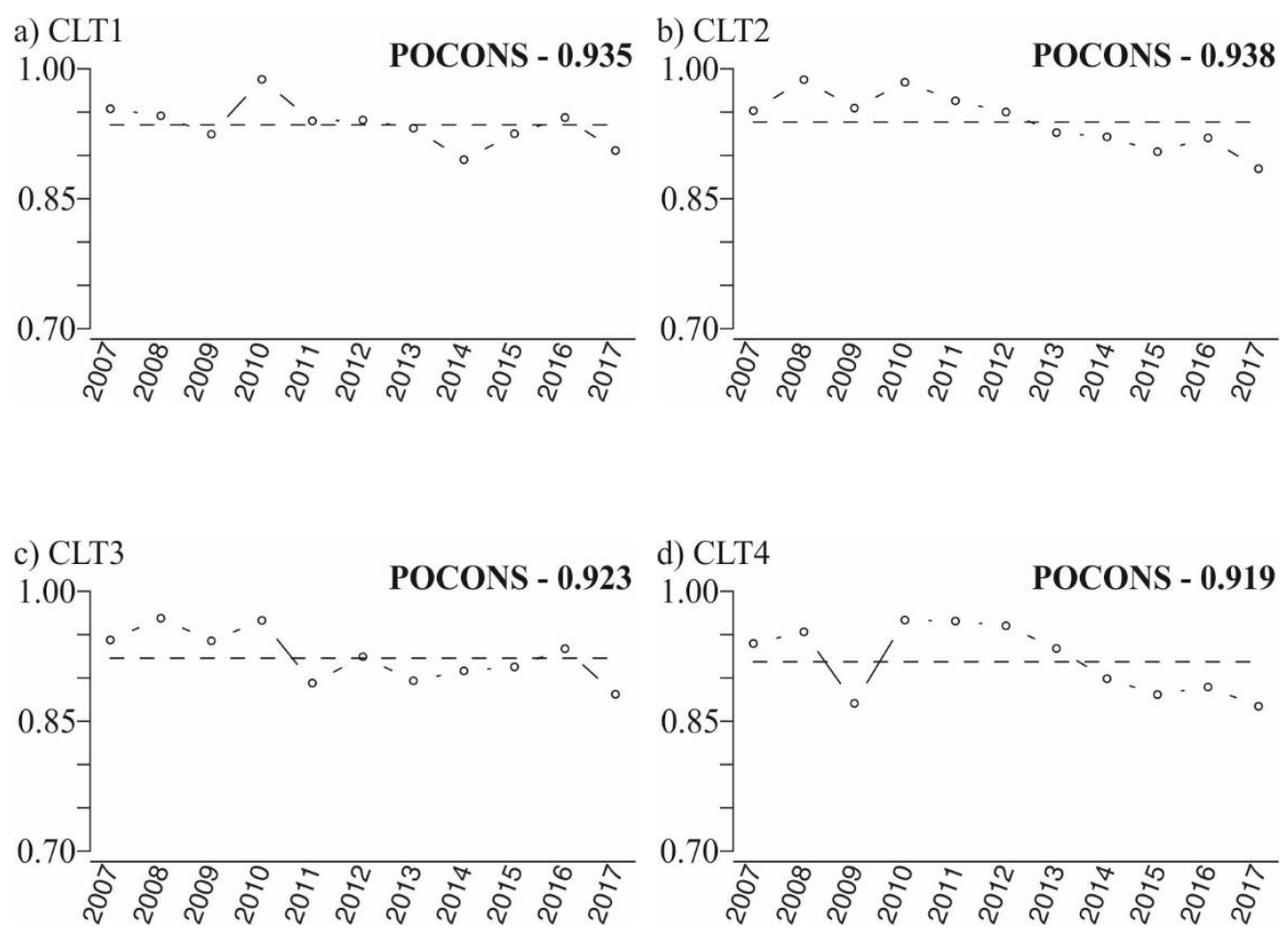

Figure 5:

BECONS values (2007-2017) for causal recipes CLT1, CLT2, CLT3, and CLT4 (Low-TEA outcome) 


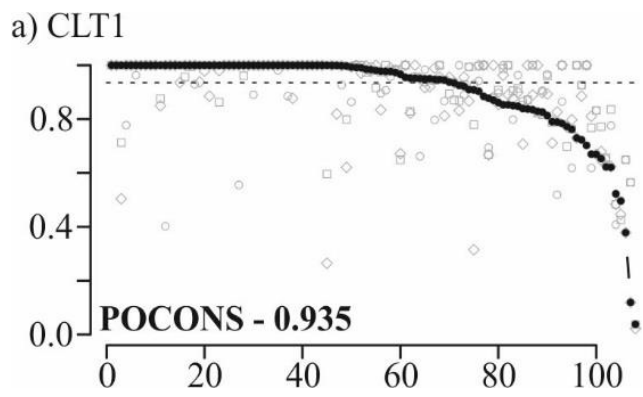

b) CLT2

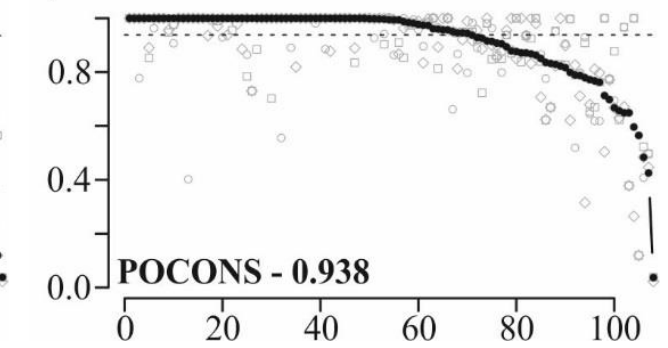

c) CLT3

d) CLT4
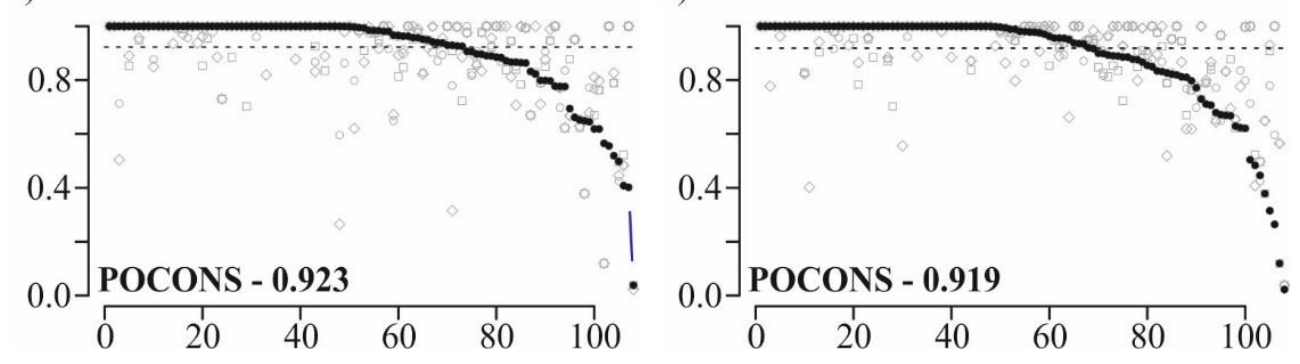

Figure 6:

WICONS values across all countries for causal recipes CLT1, CLT2, CLT3, and CLT4 (low TEA outcome) 